\title{
Erratum to: Comparison of the topical haemostatic efficacy of nano-micro particles of clinoptilolite and kaolin in a rat model of haemorrhagic injury
}

\author{
A. Bayır ${ }^{1} \cdot$ M. Eryılmaz ${ }^{2} \cdot$ M. Demirbilek ${ }^{3} \cdot$ E. B. Denkbaş ${ }^{3}$ I. Arzıman ${ }^{2} \cdot$ M. Durusu ${ }^{2}$
}

Published online: 11 July 2016

(C) Springer-Verlag Berlin Heidelberg 2016

\section{Erratum to: Eur J Trauma Emerg Surg (2016) 42:77-86 DOI 10.1007/s00068-015-0506-z}

Unfortunately, after publication of the original article, it was noticed that this article contains errors about the properties of QuikClot ${ }^{\circledR}$ and/or kaolin.

The corrected sentences about kaolin is in the 3rd paragraph (1) of the introduction part and the 5th paragraph (2) of the test material.

Also instead of the word "zeolite", it will be "aluminosilicate" as I corrected in the 4th paragraph of the introduction part and in the 3rd paragraph of the discussion part.

1. In 2008, Z-Medica company launched QuikClot Combat Gauze ${ }^{\circledR}$ (QCCG) on the market, which combines surgical gauze (rayon and polyester composition is proprietary) with kaolin particles in an aluminosilicate structure of clay minerals. QCCG was accepted as a standard topical haemostat, recommended for use on areas that could not be treated with tourniquet in the field by U.S. Department of Defense's Committee on Tactical Combat Casualty Care (CoTCCC) [11].

2. Zeolites are inorganic materials composed of aluminum, sodium, magnesium, silicate and small amounts of quartz which acts as a molecular sieve and rapidly adsorbs water in a nonchemical, physical reaction by generating heat and causes a rapid concentration of platelets and clotting factor molecules that promotes rapid clot formation [26]. However, kaolin immediately initiate the clotting process by activating factor XII and so activates factor XI and pre-kallikrein (intrinsic pathway) by electrostatic interaction when contact with blood and initiates platelet adhesion by interacting with factor XI-like protein on platelets with not producing any exothermic reaction [27].

The online version of the original article can be found under doi:10.1007/s00068-015-0506-z.

A. Bayır

aytekinbayir@hotmail.com

1 Department of Emergency Medicine, Gulhane Military Medical Academy, Haydarpasa Training Hospital, Selimiye Mh, Tıbbiye Cd, Üsküdar, 34668 Istanbul, Turkey

2 Department of Emergency Medicine, Gulhane Military Medical Academy, Ankara, Turkey

3 Department of Nanotechnology and Nanomedicine, University of Hacettepe, Ankara, Turkey 